Ifo 03

PHARMACOKINETICS AND BIOAVAILABILITY OF ORAL IFOSFAMIDE T. Wagner 1 ) and $P$. Drings 2 )

In Ifosfamide (IP) treatment usually 5-day schedules with fractionated or continously infused $I P$ administration are preferred. This is of disadvantage for out-patients and requires hospitalisation. Therefore an oral formulation of IP (500 mg crystallized IP in hard gelatine capsules) was developed. The bioavailability of the oral IP formulation was investigated in 18 patients with bronchogenic carcinoma. Oral and $i . v$. IP were applicated in a randomized sequenz on day $I$ and 3 at a dose of $1 \mathrm{~g} / \mathrm{sqm}$ and $2 \mathrm{~g} / \mathrm{sqm}$. IP determination was performed with $\mathrm{N} / \mathrm{P}$ flame ionization gas chromatography after derivatization with heptafluorobuty ric (Wagner, T., Fenneberg,K., Arzneim. Forsch.34,313,1984). Oral administered IP showed a relatively fast absorption kinetic. Peak levels were reached within one hour in both dosage groups. This also points to a fast drug release from the gelatine capsules used in our study. With exception of the absorption phase blood level curves of oral and i.v. administered IP was identical. The average half-life of IP was $5.5 \mathrm{hrs}$ after $2 \mathrm{~g} / \mathrm{sqm}$ and $5.8 \mathrm{hrs}$ at a dose of $1 \mathrm{~g} / \mathrm{sqm}$ IP with a great individual variation in both dosage groups. The overall bioavailability of oral IP (AUC p.o./AUC i.v.) was approximately $100 \%$. According to our results i.v. administration of IP especially in fractionated dosage regimes

\begin{tabular}{|c|c|c|c|c|}
\hline$I F O S F A$ & M I D E & $\begin{array}{l}t 1 / 2 \\
(\mathrm{~h})\end{array}$ & $\begin{array}{c}\mathrm{AUC} \\
\left(\mu \mathrm{molxh \times m1} 1^{-1}\right)\end{array}$ & $\frac{\text { AUC p.o. }}{\text { AUC i.v. }}$ \\
\hline $1 \underset{(\mathrm{g} / \mathrm{sqm}}{(\mathrm{n}=12)}$ & $\begin{array}{l}\text { p.o. } \\
\text { i.v. }\end{array}$ & $\begin{array}{l}5.8 \pm 2.1 \\
5.9 \pm 2.6\end{array}$ & $\begin{array}{l}79.5 \pm 28 \\
76.7 \pm 52\end{array}$ & 1.036 \\
\hline $\begin{array}{c}2 \mathrm{~g} / \mathrm{sqm} \\
(\mathrm{n}=6)\end{array}$ & $\begin{array}{l}\text { P.o. } \\
i . v .\end{array}$ & $\begin{array}{l}5.3 \pm 0.8 \\
5.7 \pm 1.1\end{array}$ & $\begin{array}{l}128.8 \pm 49 \\
134.3 \pm 51\end{array}$ & 0.959 \\
\hline
\end{tabular}

1)Klinik für Innere Medizin, Med. Universität zu Lübeck,

Ratzeburger Allee 160, D-2400 Libeck 1.

2) Medizinische Universitätsklinik Tübingen.

\section{Ifo 04}

BFFECTIVENESS OF IFOSFAMID (IF) ON HUMAN TUMOR CELLS IN CULTURE

M. Dietel, H. Arps, D. Gerding, and F. Hölzel

If has been described as potent drug inhibiting tumor growth in vivo. Our study evaluates the individuality of the in vitro interaction between IF and tumor cells. The efficacy was determined using proliferating monolayer cell cultures of explanted human tumor cells (Hölzel et al. Cancer Res Clin Oncol 109, 217-226,1985).

For the in vitro studies IF was activated by hydroxylation kindly performed by Dr. Niemeier (ASTA-Werke, Bielefeld). Cell cultures were prepared frow 10 carcinomas and 8 sarcomas characterized by DNA cytophotometry and immunohistochenistry. The antiproliferative effectiveness of IF was evaluated at 3 concentrations, $i$.e. $\mathbf{K} 2=0,5 \mu \mathrm{g} / \mathrm{ml} \equiv$ blood plasma conc. 2 h post appl., $\mathrm{K} 1=0.1 \times \overline{\mathrm{K}} 2, \mathrm{~K} 3=10 \times \mathrm{K} 2$. Sensitivity to IF was assigned when at $K 2$ growth inhibition was $>50 *$ compared to untreated control cultures. IF proved to be a highly potent anti-proliferative drug: 9 out of the 18 tumor cell strains tested were sensitive to IF in vitro. Resistance or minor growth inhibition was observed in the other cases.

The in vitro growth inhibition of IF confired the anti-proliferative potency known from clinical experiences. Positive correlation of the in vitro sensitivity to clinical results of If therapy was established in 9 out of 10 cases evaluated up to now. Since clinical staging and norphological criteria have proven unsuccessful in predicting response to chemotherapy the development of in vitro tests is neccessary to facilitate individualized chemotherapy.

PATH. INST. D. UNIV., MARTINISTR. 52, 2 HAMBURG 20 HAMB. KREBSGES., HAMB. STIFT.Z. KREBSBEKAMPFUNG
Ifo 05

SELFINDUCTION OF CYCLOPHOSPHAMIDE AND IFOSFAMIDE METABOLISM BY REPEATED HIGH DOSE TREATMENT

T. Wagnerlyand G. Ehninger 2)

Oxazaphosphorine cytostatics such as cyclophosphamide (CP) and ifosfamide (IP) require enzymatic activation to develop their alkylating properties. In man more than $80 \%$ of $\mathrm{CP}$ is metabolized and the half-life of CP mainly depends on the activation rate in the liver (Wagner, T. et al., Cancer Res.Clin. Oncol. $96,79,1980)$. In our study in 4 patients with severe aplastic anemia who received $50 \mathrm{mg} / \mathrm{kg}$ for 4 days as a conditioning treatment for bone marrow transplantation, CP halflife was shortened from $7,3 \pm 1$ hrs to $4,3 \pm 0,4$ hrs during treatment. In 7 leukemic patients $(60 \mathrm{mg} / \mathrm{kg} \times 2)$ half-life de-

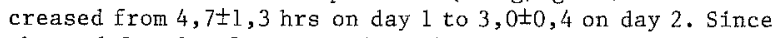
the peak levels of activated metabolites at the same time were enhanced and urinary excretion of the parent drug did not change significantly, the shortening of CP half-life is obviously due to a selfinduction of CP activation in the liver. Results of selfinduction of CP metabolism were confirmed in animal studies (NMRI mice). Sitmilar observations on a shortening of drug half-life only to a smaller extent, were made for IP aetabolism in man. During treatment of bronchogenic carcinoma with $2 \mathrm{~g} / \mathrm{sqm}$ in 6 patients a decrease of IP half-1ife from 6,4 $\pm 1,1$ hrs on day 1 to $5,4 \pm 0,7$ hrs after the second dose on day 3 was measured. At a dose of $1 \mathrm{~g} / \mathrm{sqm}$ IP $(\mathrm{n}=12)$ IP half-1ife was shortened from $6,4 \pm 2$ hrs to $5,3 \pm 1,9$ hrs. In CP treatment of breast cancer in 12 patients at a low dosage range of $175 \mathrm{mg} / \mathrm{sqm}$ no change in CP half-life could be detected during drug administration on four consecutive days $(4,16 / 4,01 / 4,14 / 3,95 \mathrm{hrs})$. Thus, acceleration of $\mathrm{CP}$ and IP metabolism during short-time treatment occured only within a high dosage range. The remarkable influence of repeated high dose application of CP and IP on their metabolism may result in a different drug toxicity and tumour response.

1 Klinik für Innere Medizin, Medizinische Universität zu Lïbeck, Ratzeburger Allee 160, D-2400 Lübeck 1.

2 Medizinische Universitätsklinik Tübingen.

\section{Ifo 06}

HIGH DOSE MESNA MAY INTERFERE WITH THE ANTITUMOUR ACTIVITY OF IFOSFAMIDE

E.A,Wist, S.Aamdal and $\emptyset . P$. Solheim

The aim of this study was to examine the possible interaction between ifosfamide and mesra. 27 patients with advanced or metastatic soft tissue sarcoma not suitable for surgery or radiation were treated with high dose ifosfamide $\left(5 \mathrm{~g} / \mathrm{m}^{2}\right)$ and concomitant mesna. The histopathological diagnoses were:unclassified soft tissue sarcoma 9, leiomyosarcoma 6 , epitheloid cell sarcoma 2 , fibrosarcoma 2 , malignant fibrous histiocytame 2, angiosarcoma 2, malignant giant cell tumour 1, synovial cell sarcoma 1 and malignant schwannoma 1.15 patients were males. 12 fenales.Median age was 42 years (range 17 - 72 years). Median Rarnovsky index was $60 \% .17$ patients had received prior chemotherapy (CYVADIC). Median time of potential follow up was 21 months. The uroprotective agent mesna was given in two different ways. Group A:Low dose $i . v$. bolus injection $400 \mathrm{mg} / \mathrm{m}^{2}$ every $4 \mathrm{hrs}$ to a total of 3 doses or to the urine being free of erythrocytes (total dose $2.8 \mathrm{~g} / \mathrm{m}^{2}$ ). Group B:High dose infusion:1 hour before ifosfamide infusion $1 \mathrm{~g} / \mathrm{m}^{2}$ was infused followed by $5 \mathrm{~g} / \mathrm{m}$ conconitant with ifosfamide followed by $400 \mathrm{mg} / \mathrm{m}$ every $4 \mathrm{hrs}$ for $24 \mathrm{hrs}$ (total dose $8.8 \mathrm{~g} / \mathrm{m}^{2}$ ). 17 pts were troated with ifosfamide and low dose mesna receiving a total of 55 courses. 10 pts received ifosfarmide with high dose mesna. Total number of courses in this group was 21. 4 pts achieved a partial response $(14.8 \%) .3$ of these had had prior chemotherapy. No change was observed in 14 pts. Duration of response was $3-13$ months. Median survival was 8 months. AIL RESPONJERS WERE TN GROUP A. In this group 11 courses was followed by microscopical henaturia. 3 courses were followed by infections. Anemia developed after 3 courses. In group B 3 courses were followed by henaturia.No infections or anemia were observed. The effect of administering either ifosfamide or ifosfamide and mesna on the lifespan of L1210 tumour-bearing DBA/2 mice was studied. Increasing the dose of ifosfamide from $80 \mathrm{mg} / \mathrm{kg}$ to $240 \mathrm{mg} / \mathrm{kg}$ caused an increase in crease in lifespan compared with non-treated animals from $40 \%$ to $100 \%$. When mesna was added in the same dose as ifosfanide this increase was lowered to 15 and $58 \%$ respectively. This clearly shows that mesna may interfere with ifosfamide in an experimental system. The uroprotective agent should therefore be used at the lowest. possible dose that prevents urothelial damage. Further studies into the optimal use of mesna /ifosfamide is clearly needed. 